\title{
Indução de resistência do mamoeiro à podridão radicular por indutores bióticos e abióticos
}

\author{
Giltembergue Macedo Tavares(1), Delson Laranjeira(1), Edna Dora Martins Newman Luz ${ }^{(2)}$, Tacila Ribeiro Silva ${ }^{(2)}$, \\ Carlos Priminho Pirovani ${ }^{(3)}$, Mário Lúcio Vilela de Resende ${ }^{(4)}$ e Pedro Martins Ribeiro Júnior ${ }^{(4)}$ \\ (1)Universidade Federal Rural de Pernambuco, Departamento de Agronomia, Área de Fitossanidade, Avenida Dom Manoel Medeiros, s/no \\ Dois Irmãos, CEP 52171-900 Recife, PE. E-mail: gilfito@yahoo.com.br, laranjeira@ufrpe.depa.br (2)Comissão Executiva de Plano da Lavoura \\ Cacaueira, Seção de Fitopatologia, Caixa Postal 07, CEP 45600-970 Ilhéus, BA. E-mail: ednadora@yahoo.com.br, tacila.ribeiro@yahoo.com.br \\ ${ }^{(3)}$ Universidade Estadual de Santa Cruz, Departamento de Ciências Biológicas, Centro de Biotecnologia e Genética, CEP $45662-000$ Ilhéus, BA. \\ E-mail: pirovani@uesc.br ${ }^{(4)}$ Universidade Federal de Lavras, Departamento de Fitopatologia, Caixa Postal 3037, CEP $37200-000$ Lavras, MG. \\ E-mail:mlucio@ufla.br, ribeirojuniorpm@yahoo.com.br
}

Resumo - O objetivo deste trabalho foi avaliar o potencial do uso de indutores de resistência bióticos e abióticos na redução da podridão radicular em mamoeiro. Mudas de mamoeiro foram pulverizadas com os fungicidas fosetil-Al, metalaxil e Mancozeb ( $\left.2 \mathrm{~g} \mathrm{~L}^{-1}\right)$, com os indutores abióticos fosfito de potássio (2,5 e $\left.5 \mathrm{~mL} \mathrm{~L}^{-1}\right)$, ácido salicílico 0,15 e $0,30 \%$, Reforce (indutor comercial) + ácido salicílico a 5\%, acibenzolar-S-metil (ASM) (0,15 e $\left.0,30 \mathrm{~g} \mathrm{~L}^{-1}\right)$, e com o indutor biótico Saccharomyces cerevisiae ( 3 e $\left.6 \mathrm{~mL} \mathrm{~L}^{-1}\right)$, três e seis dias antes da pulverização de $1 \mathrm{~mL}$ de suspensão de $10^{5}$ zoósporos $\mathrm{mL}^{-1}$ de Phytophthora palmivora. Todos os tratamentos tiveram efeito no controle da podridão de raízes em relação à testemunha, com exceção do Reforce + ácido salicílico a $5 \%$ (3 mL L-1), seis dias antes da inoculação. Os tratamentos com ASM, com exceção da dosagem $0,15 \mathrm{~g} \mathrm{~L}^{-1}$ seis dias antes da inoculação, apresentaram resultados similares aos dos fungicidas metalaxil e Mancozeb. Plantas pulverizadas com ASM apresentaram aumento de atividade da peroxidase e beta-1,3-glucanase e maior concentração de lignina que a testemunha. No entanto, esses tratamentos não tiverem efeito sobre a atividade da quitinase. O ASM é um potencial indutor de resistência a P. palmivora em mamoeiro.

Termos para indexação: Carica papaya, Phytophthora palmivora, glucanase, lignina, peroxidase, quitinase.

\section{Resistance induction to root rot in papaya by biotic and abiotic elicitors}

\begin{abstract}
The objective of this work was to evaluate the potential use of biotic and abiotic elicitors of resistance in the reduction of root rot in papaya. Papaya seedlings were sprayed with the fosetil-Al and metalaxyl and Mancozeb $\left(2 \mathrm{~g} \mathrm{~L}^{-1}\right)$ fungicides, with the potassium phosphite $\left(2.5\right.$ and $\left.5 \mathrm{~mL} \mathrm{~L}^{-1}\right)$, salicylic acid 0.15 e $0.30 \%$, Reforce (commercial product) + salicylic acid 5\%, acibenzolar-S-methyl (ASM) (0.15 and $\left.0.30 \mathrm{~g} \mathrm{~L}^{-1}\right)$ abiotic elicitors, and with the Saccharomyces cerevisiae ( 3 and $\left.6 \mathrm{~mL} \mathrm{~L}^{-1}\right)$ biotic elicitor, applied three and six days before the inoculation with $1 \mathrm{~mL}$ of $10^{5}$ zoospores $\mathrm{mL}^{-1}$ suspension of Phytophthora palmivora. All treatments were effective in controlling papaya root rot in comparison with the control, except for the Reforce + salicylic acid 5\% $\left(3 \mathrm{~mL} \mathrm{~L}^{-1}\right)$ treatment applied six days before inoculation. The treatments with the ASM elicitor, except for the $0.15 \mathrm{~g} \mathrm{~L}^{-1}$ dosage applied six days before inoculation, had control levels similar to those of the metalaxyl and Mancozeb fungicide. Plants sprayed with ASM presented increased peroxidase and beta-1,3-glucanase activity and higher lignin content than the control. However, these treatments had no effect on chitinase activity. ASM is a potential elicitor for resistance to P. palmivora in papaya.
\end{abstract}

Index terms: Carica papaya, Phytophthora palmivora, glucanase, lignin, peroxidase, chitinase.

\section{Introdução}

O mamoeiro é uma espécie tropical que encontra excelentes condições de desenvolvimento em várias regiões do Brasil. A participação brasileira na produção mundial de mamão é de $24 \%$, com um volume de 1,6 milhão de toneladas de frutos (Food and Agriculture Organization of the United Nations, 2007).
A podridão de raízes e dos frutos do mamoeiro, causada por Phytophthora palmivora (Butl.) Butl., é uma das principais enfermidades da cultura, com prejuízos econômicos que variam entre regiões. No Brasil, não existem estatísticas a respeito, mas perdas de frutos da ordem de 7 a $10 \%$ foram relatadas (Silva et al., 1999). Na estação chuvosa de 1999, com chuvas acima de $2.000 \mathrm{~mm}$, perdas elevadas 
foram observadas em plantios comerciais na Ilha de São Luis, MA, estimando-se entre 40 e $60 \%$ o número de plantas mortas em diversas propriedades (Silva, 2001).

$\mathrm{O}$ controle da podridão de raízes e frutos do mamoeiro é realizado com fungicidas. $O$ uso de produtos químicos constitui sério risco ao ambiente e à saúde humana, principalmente pela presença de resíduos tóxicos. Além disso, alguns fungos que causam doenças ao mamoeiro já adquiriram resistência aos fungicidas, principalmente aos sistêmicos, o que limita seu uso e exige pesquisas para incorporar métodos alternativos ao manejo integrado das doenças (Roberts \& Kucharek, 2005). Uma tecnologia emergente capaz de reduzir a podridão causada por Phytophthora spp. em plantas é o emprego de indutores de resistência bióticos e abióticos (Jackson et al., 2000; Dianese et al., 2007).

Indutores podem ser usados para ativar mecanismos de defesa por meio de ação direta como moléculas eliciadoras ou da indução da ativação de genes que codificam a síntese de fatores de resistência. $\mathrm{Na}$ indução da resistência, mecanismos latentes de defesa da planta são ativados por agentes indutores biológicos, físicos ou químicos (El-Ghaouth et al., 1998). A resistência induzida é um fenômeno complexo que envolve a ativação de vários processos, incluindo hipersensibilidade, barreiras estruturais, aumento da síntese de fitoalexinas e acúmulo de proteínas relacionadas à patogênese (PRs), como a hidrolase beta-1,3-glucanase, que degrada paredes celulares de patógenos fúngicos (Hammerschmidt, 1999).

$\mathrm{O}$ uso de indutores de resistência no controle de doenças de plantas tem apresentado sucesso em espécies arbóreas como Eucalyptus marginata, e é indicado no controle de oomicetos como Phytium spp. e Phytophthora spp. e de fungos causadores de podridão do colo, raiz, tronco e frutos (McDonald et al., 2001). O efeito direto do indutor de resistência no metabolismo de Phytophthora é importante na supressão dessa doença, mas não deve ser o único mecanismo de ação desses compostos no controle do patógeno, pois eles podem atuar também na ativação do sistema de defesa natural da planta (Jackson et al., 2000).
O objetivo deste trabalho foi avaliar o efeito do uso de indutores bióticos e abióticos na redução da podridão de raízes em mudas de mamoeiro.

\section{Material e Métodos}

Dois experimentos sucessivos foram realizados em condições controladas. As mudas de mamoeiro da variedade Golden foram produzidas em condições de bancada, em sistema misto de cobertura e a pleno sol, no Centro de Pesquisas do Cacau (Cepec), da Comissão Executiva de Plano da Lavoura Cacaueira (Ceplac). As análises bioquímicas foram realizadas no Laboratório de Phytophthora do Cepec, no Laboratório de Genética da Universidade Estadual de Santa Cruz (Uesc), em Ilhéus, BA, e no Laboratório de Resistência de Plantas da Universidade Federal de Lavras (Ufla), em Lavras, MG, de setembro de 2007 a agosto de 2008 .

As mudas de mamoeiro foram preparadas em bandejas com 54 tubetes com capacidade para $288 \mathrm{~cm}^{3}$ de substrato cada um, preenchidas com mistura de 50\% de Plantmax floresta (Eucatex, Brasil) e 50\% de solo esterilizado. Foram plantadas três sementes por tubete, a aproximadamente $1 \mathrm{~cm}$ de profundidade. Após a germinação, realizou-se o desbaste, e foi deixada apenas uma muda por tubete.

Utilizou-se o delineamento experimental de blocos ao acaso, com quatro repetições de 15 plantas, por tratamento. Os tratamentos foram: 0, testemunha sem inoculação de Phytophthora palmivora; 1, testemunha com inoculação de $P$. palmivora; 2, fosetil-Al $\left(2 \mathrm{~g} \mathrm{~L}^{-1}\right)$ aplicado três dias antes da inoculação (DAI) com P. palmivora; 3, metalaxil (Ridomil, Syngenta, Brasil) e Mancozeb (Dow AgroSciences, Brasil) (2 $\left.\mathrm{g} \mathrm{L} \mathrm{L}^{-1}\right) 3 \mathrm{DAI}$; 4, fosfito de potássio 40/20 (2,5 $\left.\mathrm{mL} \mathrm{L}^{-1}\right), 3 \mathrm{DAI}$; 5, fosfito de potássio 40/20 (5 mL L-1), 3 DAI; 6, fosfito de potássio 40/20 $\left(2,5 \mathrm{~mL} \mathrm{~L}^{-1}\right), 6 \mathrm{DAI}$; 7, fosfito de potássio 40/20 (5 $\left.\mathrm{mL} \mathrm{L}^{-1}\right), 6 \mathrm{DAI}$; 8, ácido salicílico $0,15 \%, 3$ DAI; 9, ácido salicílico $0,3 \%, 3 \mathrm{DAI} ; 10$, ácido salicílico $0,15 \%$, 6 DAI; 11, ácido salicílico 0,3\%, 6 DAI; 12, Reforce (produto comercial) + ácido salicílico $5 \%$ (3 mL L ${ }^{-1}$ ), 3 DAI; 13, Reforce + ácido salicílico 5\% (6 mL L $\left.\mathrm{mL}^{-1}\right), 3 \mathrm{DAI} ; 14$, Reforce + ácido salicílico 5\% (3 $\left.\mathrm{mL} \mathrm{L} \mathrm{L}^{-1}\right), 6 \mathrm{DAI} ; 15$, Reforce + ácido salicílico 5\% (6 mL L-1), 6 DAI; 16, Saccharomyces cerevisiae (Agro-Mos, Alltech, Brasil) (3 mL L-1), 3 DAI; 17,

Pesq. agropec. bras., Brasília, v.44, n.11, p.1416-1423, nov. 2009 
Saccharomyces cerevisiae (6 $\left.\mathrm{mL} \mathrm{L}^{-1}\right), 3 \mathrm{DAI} ; 18$, Saccharomyces cerevisiae (3 mL L-1), 6 DAI; 19, Saccharomyces cerevisiae $\left(6 \mathrm{~mL} \mathrm{~L}^{-1}\right), 6 \mathrm{DAI} ; 20$, acibenzolar-S-metil (ASM), (0,15 $\left.\mathrm{g} \mathrm{L}^{-1}\right) 3$ DAI; 21, $\operatorname{ASM}\left(0,3 \mathrm{~g} \mathrm{~L}^{-1}\right), 3 \mathrm{DAI} ; 22, \operatorname{ASM}\left(0,15 \mathrm{~g} \mathrm{~L}^{-1}\right), 6$ DAI e $23, \operatorname{ASM}\left(0,3 \mathrm{~g} \mathrm{~L}^{-1}\right), 6$ DAI. Os indutores e fungicidas foram aplicados por pulverização foliar das plantas, com auxílio de um borrifador.

Aos 45 dias após o plantio, as mudas foram submetidas à inoculação com $P$. palmivora, isolado 356 da coleção de Phytophthora Arnaldo Medeiros, do Cepec, comprovadamente patogênico, cultivado em meio de cultura cenoura-ágar (CA) durante sete dias, a $25 \pm 1^{\circ} \mathrm{C}$, sob luz contínua. $\mathrm{O}$ inóculo foi obtido segundo procedimento descrito por Luz et al. (2008). A concentração da suspensão foi aferida em hemacitômetro e posteriormente ajustada para $10^{5}$ zoósporos $\mathrm{mL}^{-1}$, conforme Tocafundo (2007). O substrato de cada tubete foi infestado com $1 \mathrm{~mL}$ da suspensão de zoósporos de $P$. palmivora com auxílio de uma pipeta automática. Em seguida, as plantas foram levadas para casa de vegetação climatizada, onde permaneceram por três dias para favorecer o desenvolvimento do patógeno, retornando depois para as bancadas onde se encontravam anteriormente.

A avaliação da incidência de Phytophthora foi realizada diariamente até 30 dias após a inoculação. Três amostras do sistema radicular de cada planta morta foram cultivadas em meio seletivo para confirmar a presença de $P$. palmivora como agente etiológico da enfermidade. Os níveis de controle foram estimados pelo percentual de sobrevivência das mudas.

Para quantificação de proteínas totais e atividade das enzimas beta-1,3-glucanase, peroxidase e quitinase, cinco e dez dias após a inoculação do patógeno, foi coletado 1,5 $\mathrm{g}$ de folhas das plantas de cada tratamento. Imediatamente após cada coleta, as folhas foram congeladas em nitrogênio líquido e armazenadas a $-20^{\circ} \mathrm{C}$ até o momento da maceração. As folhas de cada tratamento foram maceradas em almofariz com $15 \mathrm{~mL}$

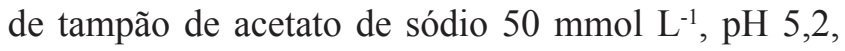
com $0,07 \mathrm{~g}$ de antioxidante polivinilpirrolidona (PVP). Em seguida, a mistura foi filtrada em pano de trama fina e a suspensão foi centrifugada a $14.000 \mathrm{~g}$ por $15 \mathrm{~min}$, a $4^{\circ} \mathrm{C}$. O sobrenadante coletado de cada amostra foi transferido para microtubos de $2 \mathrm{~mL}$ e mantido a $-80^{\circ} \mathrm{C}$ até o momento das análises. As proteínas solúveis contidas nos extratos foram aferidas pelo ensaio de
Bradford (1976), utilizando-se um padrão de albumina sérica bovina (BSA).

A atividade de peroxidase foi determinada de acordo com o método de Kar \& Mishra (1976), utilizando guaiacol em presença de peróxido de hidrogênio, e os resultados foram expressos em unidade de atividade enzimática por miligrama de proteína por minuto. A atividade da quitinase foi determinada pela adição de $70 \mu \mathrm{L}$ do extrato enzimático à solução com $100 \mu \mathrm{L}$ de acetato de sódio $50 \mathrm{mmol} \mathrm{L}^{-1}, \mathrm{pH} 5,2$ e de $50 \mu \mathrm{L}$ do substrato específico para quitinase CM-Chitin-RBV (Loewe Biochemica $\mathrm{GmbH}$, Alemanha) $\left(2 \mathrm{mg} \mathrm{mL}^{-1}\right)$, em microplacas de 96 cavidades com capacidade de $350 \mu \mathrm{L}$. Depois da incubação a $38^{\circ} \mathrm{C}$ por $120 \mathrm{~min}$, as amostras foram acidificadas com $50 \mu \mathrm{L}$ de $\mathrm{HC} 1 \mathrm{~N}$, resfriadas em banho de gelo por 10 min e centrifugadas a $1.450 \mathrm{~g}$ por $10 \mathrm{~min}$. Uma alíquota de $200 \mu \mathrm{L}$ do sobrenadante de cada amostra foi transferida para novas microplacas para leitura a $492 \mathrm{~nm}$, em um leitor compatível com EIA (Wirth \& Wolf, 1990).

A atividade de beta-1,3-glucanases foi medida seguindo método análogo, apenas com a troca do substrato para CM-Curdlan-RBB (Loewe Biochemica $\mathrm{GmbH}$, Alemanha) (4 $\left.\mathrm{mg} \mathrm{mL}^{-1}\right)$ e com o ajuste da alíquota do extrato enzimático para $100 \mu \mathrm{L}$ (deduzido o volume do tampão de acetato, a fim de se ajustar o volume final para $310 \mu \mathrm{L}$ por cavidade). Para promover a ação hidrolítica da beta-1,3-glucanase, foi adotado tempo de incubação de $38^{\circ} \mathrm{C}$ por $120 \mathrm{~min}$. As amostras foram, então, medidas fotometricamente em filtro de $620 \mathrm{~nm}$ de um leitor EIA. Todos os ensaios foram realizados em triplicata.

O segundo experimento, feito com base no experimento anterior, foi realizado em delineamento de blocos ao acaso, com dois tratamentos, três repetições e quatro plantas por tratamento. Os tratamentos foram: pulverização do indutor $\operatorname{ASM}\left(0,3 \mathrm{~g} \mathrm{~L}^{-1}\right)$; e testemunha, pulverizada apenas com água. No quinto dia após a aplicação dos tratamentos, as mudas foram submetidas à inoculação com $P$. palmivora, realizada conforme descrito no primeiro experimento.

A coleta das folhas de mamoeiro foi realizada 0 , $1,2,3,4,4,5,4,75,5,5,25,5,5,6,7,8,9$ e 10 dias após a pulverização (DAP), para determinar a atividade enzimática (beta-1,3-glucanase, peroxidase e quitinase). Para a determinação de lignina, foram coletadas amostras de raízes no momento da pulverização e dez dias depois. O conteúdo de lignina 
foi determinado conforme descrito por Stadnik (1999), por meio do ensaio com ácido tioglicólico (Monties, 1989), e os resultados foram expressos em miligrama de lignina por grama de matéria fresca.

Os dados foram submetidos à analise de variância e as médias foram comparadas pelo teste de Tukey a 5\% de probabilidade, pelo SAS (SAS Institute, 1992).

\section{Resultados e Discussão}

No primeiro experimento, nas plantas pulverizadas com os indutores de resistência, os valores da incidência da doença atingiram, de maneira geral, um patamar máximo entre o $10^{\circ}$ e o $15^{\circ}$ dias após a inoculação de $P$. palmivora (DAI), e a mortalidade máxima das plantas ocorreu até o $30^{\circ}$ DAI. Nesta ocasião, uma das parcelas da testemunha inoculada apenas com o patógeno (tratamento 1) chegou a atingir 100\% de mortalidade (Tabela 1). Durante esse período, o maior percentual de mortalidade $(91,7 \%)$ foi constatado nas testemunhas inoculadas apenas com $P$. palmivora.

Todas os tratamentos testados reduziram a mortalidade das plantas, com exceção de Reforce + ácido salicílico 5\% (3 mL L-1, 6 DAI) (Tabela 1). A redução da incidência da doença foi, em geral, maior nos tratamentos com o indutor ASM, nas diferentes doses e épocas de aplicação, apesar de alguns deles não terem diferido estatisticamente dos tratamentos $2,7,9,16$, 12,17 e 8 , que não continham ASM. As percentagens de sobrevivência de plantas foram de $68,3 \%$ para o tratamento 21 (ASM 0,3 $\mathrm{g} \mathrm{L}^{-1}, 3 \mathrm{DAI}$ ), 66,7\% para o tratamento 20 (ASM 0,15 $\mathrm{g} \mathrm{L}^{-1}, 3 \mathrm{DAI}$ ), 65,3\% para o tratamento 23 (ASM 0,3 $\mathrm{g} \mathrm{L}^{-1}, 6 \mathrm{DAI}$ ) e $56,7 \%$ para o tratamento 22 (ASM 0,15 $\left.\mathrm{g} \mathrm{L}^{-1}, 6 \mathrm{DAI}\right)$. Os tratamentos

Tabela 1. Percentagem de sobrevivência de plantas de mamoeiro da variedade Golden, submetidas a diferentes tratamentos com indutores de resistência, 30 dias após a inoculação com Phytophthora palmivora, e atividade das enzimas beta-1,3glucanase e peroxidase (unidade de atividade enzimática por miligrama de proteína por min) em folhas coletadas cinco e dez dias após a inoculação(1).

\begin{tabular}{|c|c|c|c|c|c|}
\hline \multirow[t]{2}{*}{ Tratamento $^{(2)}$} & \multirow{2}{*}{$\begin{array}{c}\text { Sobrevivência } \\
(\%)\end{array}$} & \multicolumn{2}{|c|}{ Beta-1,3-glucanase } & \multicolumn{2}{|c|}{ Peroxidase } \\
\hline & & 5 dias & 10 dias & 5 dias & 10 dias \\
\hline 0 & - & $0,051 \mathrm{e}$ & $0,002 b$ & $0,618 \mathrm{i}$ & 1,834efghi \\
\hline 1 & 8,3 & $0,052 \mathrm{de}$ & $0,003 b$ & 1,706efghi & $0,850 \mathrm{i}$ \\
\hline 2 & $53,3 \mathrm{bcd}$ & $0,054 \mathrm{de}$ & $0,004 \mathrm{~b}$ & 1,609efghi & $1,077 \mathrm{ghi}$ \\
\hline 3 & $83,3 \mathrm{a}$ & $0,075 \mathrm{bcde}$ & $0,005 b$ & 1,850efghi & 1,288 fghi \\
\hline 4 & $33,3 \mathrm{cde}$ & 0,098 abcde & $0,004 b$ & 2,231 efgh & $2,956 \mathrm{cdefgh}$ \\
\hline 5 & $28,3 \mathrm{cde}$ & $0,082 \mathrm{bcde}$ & $0,004 b$ & 1,706efghi & 1,963defghi \\
\hline 6 & $35,0 \mathrm{cde}$ & $0,119 \mathrm{abcd}$ & $0,003 b$ & $2,144 \mathrm{efgh}$ & $3,175 \mathrm{cdefg}$ \\
\hline 7 & 50,0 bcde & 0,096abcde & $0,004 b$ & 1,913 efghi & 2,073defghi \\
\hline 8 & $41,6 \mathrm{cde}$ & $0,066 \mathrm{de}$ & $0,004 b$ & $1,338 \mathrm{ghi}$ & 2,383cdefghi \\
\hline 9 & $48,4 \mathrm{bcde}$ & $0,065 \mathrm{de}$ & $0,004 b$ & $0,995 \mathrm{hi}$ & 1,455 efghi \\
\hline 10 & $36,7 \mathrm{cde}$ & $0,054 \mathrm{de}$ & $0,004 b$ & $1,115 \mathrm{hi}$ & 1,667efghi \\
\hline 11 & $36,6 \mathrm{cde}$ & 0,091abcde & $0,005 b$ & 1,638 efghi & 3,014 cdefgh \\
\hline 12 & $46,7 \mathrm{bcde}$ & $0,091 \mathrm{bcde}$ & $0,005 b$ & $2,173 \mathrm{efgh}$ & 2,000defghi \\
\hline 13 & $35,0 \mathrm{cde}$ & $0,086 \mathrm{bcde}$ & $0,003 b$ & $1,036 \mathrm{hi}$ & 2,640 cdefghi \\
\hline 14 & $26,6 \mathrm{ef}$ & 0,100 abcde & $0,003 b$ & 1,418fghi & 2,188defghi \\
\hline 15 & $40,0 \mathrm{cde}$ & $0,080 \mathrm{bcde}$ & $0,002 b$ & 1,637 efghi & $1,043 \mathrm{hi}$ \\
\hline 16 & $48,4 \mathrm{bcde}$ & 0,101 abcde & $0,004 b$ & $2,769 \mathrm{def}$ & 3,493 cde \\
\hline 17 & $41,7 \mathrm{cde}$ & $0,067 \mathrm{cde}$ & $0,004 b$ & $2,758 \mathrm{def}$ & 1,333fghi \\
\hline 18 & 40,0 cde & $0,060 \mathrm{de}$ & $0,003 b$ & $2,495 \mathrm{efg}$ & $3,324 \mathrm{cdef}$ \\
\hline 19 & 40,0 cde & $0,114 \mathrm{abcde}$ & $0,004 b$ & $2,924 \mathrm{de}$ & 1,689efghi \\
\hline 20 & $66,7 \mathrm{ab}$ & $0,158 \mathrm{a}$ & $0,015 \mathrm{a}$ & $4,023 \mathrm{~cd}$ & $5,913 \mathrm{ab}$ \\
\hline 21 & $68,3 \mathrm{ab}$ & $0,135 \mathrm{ab}$ & $0,015 \mathrm{a}$ & $5,554 \mathrm{~b}$ & $3,956 \mathrm{bcd}$ \\
\hline 22 & $56,7 \mathrm{bcd}$ & 0,104 abcde & $0,011 \mathrm{a}$ & $5,162 b c$ & $4,482 a b c$ \\
\hline 23 & $65,3 \mathrm{abc}$ & $0,134 \mathrm{abc}$ & $0,014 \mathrm{a}$ & $7,375 \mathrm{a}$ & $6,412 \mathrm{a}$ \\
\hline
\end{tabular}

${ }^{(1)}$ Médias seguidas de letras iguais nas colunas não diferem entre si pelo teste de Tukey, a 5\% de probabilidade. ${ }^{(2)}$ Tratamentos: 0 , testemunha sem inoculação de P. palmivora; 1, testemunha inoculada com P. palmivora; 2, fosetil-Al (2 $\left.\mathrm{g} \mathrm{L}^{-1}\right) ; 3$, metalaxil e Mancozeb (2 $\left.\mathrm{g} \mathrm{L}^{-1}\right), 3$ dias antes da inoculação (DAI) com P. palmivora; 4, fosfito de potássio 40/20 (2,5 $\left.\mathrm{mL} \mathrm{L}^{-1}\right), 3$ DAI; 5, fosfito de potássio 40/20 (5 $\left.\mathrm{mL} \mathrm{L}^{-1}\right), 3 \mathrm{DAI} ; 6$, fosfito de potássio 40/20 (2,5 $\left.\mathrm{mL} \mathrm{L}^{-1}\right)$, 6 DAI; 7, fosfito de potássio 40/20 (5 mL L-1), 6 DAI; 8, ácido salicílico 0,15\%, 3 DAI; 9, ácido salicílico 0,3\%, 3 DAI; 10, ácido salicílico $0,15 \%, 6$ DAI; 11, ácido salić́lico 0,3\%, 6 DAI; 12, Reforce e ácido salić́lico 5\% (3 mL L-1), 3 DAI; 13, Reforce e ácido salicílico 5\% (6 mL L-1), 3 DAI; 14 , Reforce e ácido salicílico 5\% (3 mL L $\left.\mathrm{mL}^{-1}\right), 6 \mathrm{DAI}$; 15, Reforce e ácido salić́lico 5\% (6 mL L-1), 6 DAI; 16, Saccharomyces cerevisiae (3 mL L-1), 3 DAI; 17, Saccharomyces cerevisiae (6 mL L-1), 3 DAI; 18, Saccharomyces cerevisiae (3 mL L $\left.{ }^{-1}\right), 6$ DAI; 19, Saccharomyces cerevisiae (6 mL L-1), 6 DAI; 20 , Acibenzolar-S-metil (ASM), (0,15 $\left.\mathrm{g} \mathrm{L}^{-1}\right) 3$ DAI; 21, ASM (0,3 g L-1), 3 DAI; 22, ASM (0,15 g L-1), 6 DAI e 23, ASM (0,3 g L-1), 6 DAI. 
20,21 e23 não diferiram estatisticamente do tratamento 3 (metalaxil e Mancozeb, fungicida padrão utilizado no controle de doenças causadas por Phytophthora spp.), cuja eficiência de controle foi a maior observada ( $83,3 \%$ de sobrevivência de plantas). O tratamento 22 , embora com eficiência estatisticamente menor que a do fungicida padrão, apresentou controle similar ao do fungicida fosetil-Al (tratamento 2), também utilizado no controle de $P$. palmivora em mamoeiro. O tratamento com metalaxil e Mancozeb diferiu de todos os demais indutores de resistência.

A testemunha inoculada com $P$. palmivora (tratamento 1), apresentou taxa de sobrevivência das plantas muito reduzida, de apenas $8,3 \%$, o que demonstra a elevada patogenicidade do isolado utilizado. Amostras de plantas mortas dos tratamentos que receberam inoculação de $P$. palmivora foram isoladas em meio seletivo, onde se constatou o desenvolvimento de colônias de patógeno. Nenhuma planta do tratamento 0 (testemunha sem inoculação) morreu ou apresentou sintomas.

Controle de doenças fúngicas pelo uso do ASM tem sido comumente reportado. Rodrigues et al. (2006), ao aplicar o ASM em caupi cinco dias após a germinação, observaram $68,9 \%$ de controle de Fusarium oxysporum f. sp. tracheiphilum na cultivar BR-17 Gurgua, suscetível, e 71,59\% de controle na cultivar IPA-206, que apresenta resistência intermediária. Já Danner et al. (2008), ao testar a eficiência do ASM no patossistema Monilinia fructicola e pêssego, verificaram eficiência de $24,9 \%$ do controle.

Paralelamente à redução da incidência da podridão de raiz do mamoeiro, promovida pelo indutor abiótico ASM nas diferentes doses e intervalos (tratamentos 20, 21 e 23), observou-se também, nas folhas coletadas cinco dias após a inoculação, aumento das atividades da enzima beta-1,3-glucanase (Tabela 1). Além dos tratamentos com ASM, o tratamento 6 (fosfito de potássio $2,5 \mathrm{~mL} \mathrm{~L}^{-1}, 6 \mathrm{DAI}$ ) também mostrou aumento da atividade dessa enzima na mesma coleta. Na segunda coleta de folhas, dez dias após a inoculação, observou-se uma redução de aproximadamente dez vezes na atividade de beta-1,3-glucanase, em todos os tratamentos, em relação à primeira coleta. Entretanto, os tratamentos com ASM (20, 21, 22 e 23) proporcionaram maior atividade da beta-1,3-glucanase que os demais tratamentos, os quais proporcionaram atividades similares às observadas na testemunha. A redução da atividade da enzima beta-1,3-glucanase dez dias após a inoculação também foi observada por Rodrigues et al. (2006) ao trabalhar com o patossistema Fusarium oxysporum f. sp. tracheiphilum e caupi.

$\mathrm{Na}$ determinação da atividade da enzima peroxidase, na primeira coleta de folhas (Tabela 1), constatou-se que os tratamentos com ASM apresentaram maior atividade dessa enzima que os demais tratamentos, com destaque para o tratamento 23 (ASM 0,3 $\mathrm{g} \mathrm{L}^{-1}$, 6 DAI) que diferiu estatisticamente de todos os demais. Os tratamentos 19, 17 e 16, embora não tenham diferido do tratamento 20 (ASM 0,15 $\mathrm{g} \mathrm{L}^{-1}$, 3 DAI), em relação à atividade de peroxidase, não diferiram estatisticamente também da testemunha com inoculação do patógeno (tratamento 1). Na segunda coleta de folhas, constatou-se que a atividade da enzima manteve-se praticamente constante, mas os tratamentos com ASM mantiveram atividade, em geral, significativamente maior que os demais tratamentos; os tratamentos $23\left(0,3 \mathrm{~g} \mathrm{~L}^{-1}, 6 \mathrm{DAI}\right)$ e $20\left(0,15 \mathrm{~g} \mathrm{~L}^{-1}, 3 \mathrm{DAI}\right)$ apresentaram os melhores resultados para este parâmetro. Os tratamentos 2, 3, $5,7,8,9,10,12,13,14,15,17$ e 19 não diferiram significativamente das testemunhas. Cavalcanti et al. (2006), ao trabalhar com o patossistema tomateiro e Xanthomonas vesicatoria, também constataram aumento da atividade da enzima peroxidase após a pulverização com o ASM.

Constatou-se, no segundo experimento, que as plantas de mamoeiro pulverizadas com $\operatorname{ASM}\left(0,3 \mathrm{~g} \mathrm{~L}^{-1}\right)$ apresentaram aumento significativo da atividade da enzima beta-1,3-glucanase a partir do primeiro dia após a pulverização (Figura $1 \mathrm{~A}$ ). A atividade dessa enzima teve o máximo aumento no quinto DAP. Já as plantas pulverizadas com água e submetidas à inoculação manifestaram baixa tendência de aumento de atividade de beta-1,3-glucanase 5,25 DAP. Consta00tou-se, também, que níveis elevados na atividade da beta-1,3-glucanase foram associados à redução substancial da podridão das raízes, o que denota um provável envolvimento de beta-1,3-glucanase na redução da doença verificada no primeiro experimento. 
A enzima beta-1,3-glucanase é uma proteína relacionada à patogênese (proteína $\mathrm{PR}$ ), capaz de hidrolisar células fúngicas, que age diretamente ou por meio da liberação de fragmentos oligossacarídicos do fungo ou da parede celular da planta que eliciam respostas secundárias de defesa da planta,
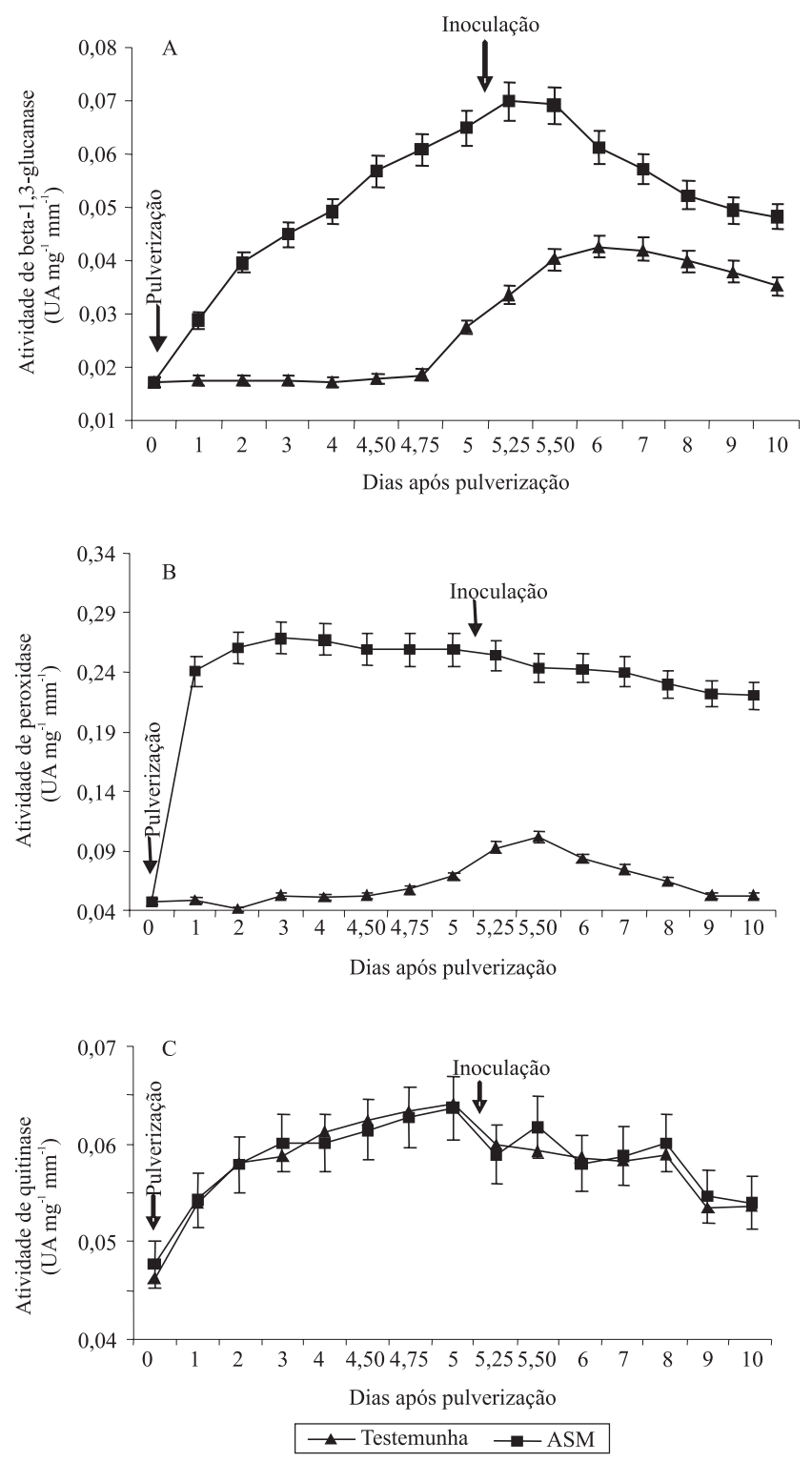

Figura 1. Atividade das enzimas beta-1,3-glucanase (A), peroxidase (B) e quitinase (C), em folhas de mamoeiro da variedade Golden inoculadas com Phytophthora palmivora, cinco dias após a pulverização com o indutor acibenzolarS-metil (ASM, 0,3 $\mathrm{g} \mathrm{L}^{-1}$ ) e com água (testemunha). Barras indicam erro-padrão da média. Setas indicam o momento da pulverização e da inoculação do patógeno. que caracterizam a ação antimicrobiana (Durrant \& Dong, 2004).

Plantas pulverizadas com ASM também apresentaram aumento significativo na atividade da peroxidase a partir do primeiro DAP e apresentaram picos de atividade no terceiro dia. A partir do quarto DAP, observou-se início da redução significativa de atividade, porém ainda com atividade significativamente superior à do controle (Figura 1 B). As plantas testemunha, inoculadas apenas com o patógeno, apresentaram aumento significativo da atividade de peroxidase somente após a inoculação, o que indica que isso ocorreu pelo estímulo à presença do patógeno. A curva de atividade da peroxidase da testemunha, no entanto, é bem mais baixa que a do tratamento com ASM. A atividade de peroxidase tem sido associada a uma variedade de processos relacionados à defesa em plantas, como reações de hipersensibilidade, lignificação e suberização (Silva, 2007). Pereira et al. (2008) observaram picos de atividade de peroxidase aos 8 e 18 DAP, em plantas de cacau tratadas com ASM visando ao controle da murcha-de-verticílio. De fato, Cavalcanti et al. (2006) constataram que medidas da atividade da peroxidase e beta-1,3-glucanase são os primeiros indicativos da ativação de respostas de defesa das plantas, a partir da aplicação do eliciador.

As plantas manifestaram atividade de quitinase depois da pulverização com ASM, mas sem diferir do tratamento controle com inoculação. Observouse um aumento inicial até o quinto DAP, a partir do qual houve queda significativa da atividade (Figura $1 \mathrm{C}$ ). O fato de o ASM não ter induzido a atividade das proteínas PR quitinases é vantajoso no que se refere ao patossistema mamoeiro e P. palmivora, pois esse patógeno não possui quitina na parede celular e a ativação dessa enzima poderia acarretar um custo energético para planta (Heil et al., 2000).

Em relação às concentrações de lignina total, no momento da pulverização não houve diferença significativa entre as médias da testemunha (5,16 $\mathrm{mg}$ de lignina por grama de matéria fresca) e do tratamento com ASM $(5,18 \mathrm{mg}$ de lignina por grama de matéria fresca), pelo teste de Tukey a 5\% de probabilidade. Na segunda coleta de raízes, aos dez DAP, plantas tratadas com ASM apresentaram concentrações de lignina significativamente 
superiores $(9,87 \mathrm{mg}$ de lignina por grama de matéria fresca) às da testemunha $(6,55 \mathrm{mg}$ de lignina por grama de matéria fresca). Isso pode ter ocorrido devido ao efeito do indutor e ao reconhecimento do patógeno pelo hospedeiro. Segundo Kúc (2001), a lignificação da parede celular é caracterizada como uma das reações desencadeadas pelo sistema de defesa da planta, para impedir a penetração ou restringir a colonização dos tecidos por patógenos.

\section{Conclusões}

1. Os indutores fosfito de potássio, ácido salicílico, Reforce + ácido salicílico e Saccharomyces cerevisiae conferem baixa capacidade de proteção a plantas de mamoeiro contra Phytophthora palmivora.

2. O acibenzolar-S-metil confere proteção a plantas de mamoeiro contra Phytophthora palmivora.

3. O acibenzolar-S-metil promove aumento na atividade das enzimas beta-1,3-glucanase e peroxidase, relacionadas à patogênese e ao acúmulo de lignina em raízes de plântulas de mamoeiro, mas não promove aumento na atividade da quitinase.

\section{Agradecimentos}

Ao Conselho Nacional de Desenvolvimento Científico e Tecnológico, pelo apoio financeiro.

\section{Referências}

BRADFORD, M.M. A rapid and sensitive method for the quantification of microgram quantities of protein utilizing the principle of protein-dye binding. Analytical Biochemistry, v.72, p.248-254, 1976.

CAVALCANTI, F.R.; RESENDE, M.L.V. de; PEREIRA, R.B.; COSTA, J. de C. do B.; CARVALHO, C.P. da S. Atividades de quitinase e beta-1,3-glucanase após eliciação das defesas do tomateiro contra a mancha-bacteriana. Pesquisa Agropecuária Brasileira, v.41, p.1721-1730, 2006.

DANNER, M.A.; SASSO, S.A.Z.; MEDEIROS, J.G.S.; MARCHESE, J.A.; MAZARO, S.M. Indução de resistência à podridão-parda em pêssegos pelo uso de eliciadores em pós-colheita. Pesquisa Agropecuária Brasileira, v.43, p.793-799, 2008.

DIANESE, A.C.; BLUM, L.E.B.; DUTRA, J.B.; LOPES, L.F.; SENA, M.C.; FREITAS, L.F.; YAMANISHI, O.K. Redução da podridão do pé (Phytophthora palmivora) do mamoeiro (Carica papaya) por fosfitos. Fitopatologia Brasileira, v.32, p.166, 2007.
DURRANT, W.E.; DONG, X. Systemic acquired resistance. Annual Review of Phytopathology, v.42, p.185-209, 2004.

EL-GHAOUTH, A.; WILSON, C.L.; WISNIEWSKI, M. Ultrastructural and cytochemical aspects of the biological control of Botrytis cinerea by Candida saitoana in apple fruit. Phytopathology, v.88, p.282-291, 1998.

FOOD AND AGRICULTURE ORGANIZATION OF THE UNITED NATIONS. Papaya production and harvested area. Disponível em: <http://faostat.fao.org/>. Acesso em: 19 mar. 2007.

HAMMERSCHMIDT, R. Induced disease resistance: how do induced plants stop pathogens? Physiology and Molecular Plant Pathology, v.55, p.77-84, 1999.

HEIL, M.; HILPERT, A.; KAISER, W.; LINSENMAIR, K.E. Reduced growth and seed set following chemical induction of pathogen defense: does systemic acquired resistance (SAR) incur allocation costs? Journal of Ecology, v.88, p.645-654, 2000 .

JACKSON, T.J.; BURGESS, T.; COLQUHOUN, I.; HARDY, G.E. Action of the fungicide phosphite on Eucalyptus marginata inoculated with Phytophthora cinnamomi. Plant Pathology, v.49, p.147-154, 2000.

KÚC, J. Concepts and direction of induced systemic resistance in plants and its application. European Journal of Plant Pathology, v.107, p.7-12, 2001.

LUZ, E.D.M.N.; SILVA, S.D.V.M.; BEZERRA, J.L.; SOUZA, J. de T.; SANTOS A.F. dos. Glossário ilustrado de Phytophthora: técnicas especiais para o estudo de oomicetos. Itabuna: FAPESB, 2008. 126p.

MCDONALD, A.E.; GRANT, B.R.; PLAXTON, W.C. Phosphite (phosphorous acid): its relevance in the environment and agriculture and influence on plant phosphate starvation response. Journal of Plant Nutrition, v.24, p.1505-1519, 2001.

MONTIES, B. Lignins. In: DEY, P.M.; HARBORNE, J.B. (Ed.). Methods in plant biochemistry. New York: Academic Press, 1989. p.113-158.

PEREIRA, R.B.; RESENDE, M.L.V. de; RIBEIRO JÚNIOR, P.M.; AMARAL, D.R.; LUCAS, G.C.; CAVALCANTI, F.R. Ativação de defesa em cacaueiro contra a murcha-de-verticílio por extratos naturais e acibenzolar-S-metil. Pesquisa Agropecuária Brasileira, v.43, p.171-178, 2008.

ROBERTS, P.; KUCHAREK, T. Florida plant disease management guide: cucumber. Disponível em: <http://edis. ifas.ufl.edu>. Acesso em: 15 set. 2005.

RODRIGUES, A.A.C.; BEZERRA NETO, E.; COELHO, R.S.B. Indução de resistência a Fusarium oxysporum f. sp. tracheiphilum em caupi: eficiência de indutores abióticos e atividade enzimática elicitada. Fitopatologia Brasileira, v.31, p.492-499, 2006.

SAS INSTITUTE. SAS/STAT software: changes and enhancement. Release 6.07. Cary: SAS Institute, 1992.

SILVA, G.S. Podridão das raízes e dos frutos do mamoeiro. In: LUZ, E.D.M.N; SANTOS, A.F. dos; MATUSUOKA, K.; 
BEZERRA, J.L. (Ed.). Doenças causadas por Phytophthora no Brasil. Campinas: Rural, 2001. p.413-432.

SILVA, G.S.; URBEN, A.F.; DOIHARA, I.P. A ocorrência de Phytophthora palmivora em mamoeiro no Estado do Maranhão. Fitopatologia Brasileira, n.18, p.32, 1999.

SILVA, R.F. Indução de resistência em plantas de berinjela e tomate por Lentinula edodes e Agaricus blazei contra bactérias causadoras de murchas (Ralstonia solanacearum) e cancro (Clavibacter michiganensis subsp. michiganensis). 2007. 109p. Tese (Doutorado) - Escola Superior de Agricultura Luiz de Queiroz, Piracicaba.
STADNIK, M.J. Induction of resistance in wheat by a benzothiadiazole derivative against the powdery mildew (Blumeria graminis f. sp.tritici): practical aspects and mechanisms of action. 1999. 138p. Thesis (Ph.D) - University of Hohenheim, Stuttgart.

TOCAFUNDO, F. Avaliação de isolados de Trichoderma spp. no controle de Phytophthora palmivora em mamoeiro. 2007. 54p. Dissertação (Mestrado) - Universidade Estadual do Sudoeste da Bahia, Itabuna.

WIRTH, S.J.; WOLF, G.A. Dye-labelled substrates for the assay and detection of chitinase and lysozyme activity. Journal of Microbiological Methods, v.12, p.197-205, 1990.

Recebido em 10 de fevereiro de 2009 e aprovado em 29 de outubro de 2009 